\title{
FERNÁNDEZ, ENCARNACIÓN. DE VITORIA A LIBIA: REFLEXIONES EN TORNO A LA RESPONSABILIDAD DE PROTEGER. GRANADA: COMARES, 2013. (COLECCIÓN FILOSOFIA, DERECHO Y SOCIEDADE).
}

\section{Edson Ferreira de Carvalho*}

O livro em epígrafe, de autoria da Profa. Dra. Encarnación Fernández, da Faculdade de Direito da Universidade de Valência, Espanha, foi publicado em 2013 pela Editora Comares, com sede em Granada. A obra versa sobre um dos temas mais candentes da atualidade no âmbito do Direito Internacional, especialmente no que tange à defesa dos direitos humanos em situações de graves e massivas violações.

O terceiro milênio, caracterizado pelo processo de globalização, ensejou preciosas oportunidades e expectativas quanto à afirmação da consciência do destino comum da humanidade. Esperava-se que a facilidade de comunicação e interação entre pessoas de diferentes culturas promoveria relações de cooperação e solidariedade, ao mesmo tempo em que, de forma pacífica, seriam desarticuladas relações históricas de dominação e exclusão. Dessa forma, a convivência harmoniosa entre etnias, povos, culturas e países alcançaria dimensões planetárias, criandose um ambiente de paz e prosperidade para toda a humanidade.

Desafortunadamente, a sociedade global vigente é bem diferente da imaginada pelos defensores dos direitos humanos. O sistema econômico agravou sua lógica concentradora e excludente, ao passo que surgiram inúmeros conflitos de extraordinária violência. Tais desordens aumentaram o clima de insegurança da comunidade internacional e multiplicaram as crises humanitárias. Bósnia, Kosovo, Afeganistão, Iraque, Líbia, Síria e Egito, são os exemplos mais dramáticos das tragédias que fazem regredir a espécie humana aos mais condenáveis instintos agressivos.

\footnotetext{
* Professor do Departamento de Direito da Universidade Federal de Viçosa. Mestre em Direito pela UFSC. Doutorando em Direito pela Universidade de Valência, Espanha.
} 
Conflitos como tais atentam contra obrigações erga omnes consagradas no Direito Internacional dos Direitos Humanos, pois provocam violações graves e sistemáticas contra a dignidade humana. Nesse contexto, emergem questões de altíssima relevância teórica e prática. Quais respostas políticas e jurídicas devem ser dadas a essas situações de extrema gravidade? Quais mecanismos institucionais devem ser estabelecidos para proteger as vítimas e exigir responsabilidade internacional do estado e penal de indivíduos que promovem barbaridades contra os direitos humanos? O livro convida à reflexão sobre essas questões e abre espaço para a criação de mecanismos de enfrentamento das múltiplas expressões de violência de poder acobertadas pelo princípio da soberania estatal e da não ingerência em assuntos internos.

O livro da Dra. Encarnación Fernández trata da intervenção humanitária e da responsabilidade de proteger populações vítimas de violações de direitos humanos massivas e graves, dando especial atenção à delicada questão do uso da força com vistas à proteção dos direitos humanos no território de terceiro Estado. $\mathrm{O}$ uso da força foi proibido, como regra geral, pela da Carta das Nações Unidas, em 1945. A proibição da ameaça e do uso da força nas relações internacionais só admite duas exceções, a legítima defesa e a autorização do uso da força pelo Conselho de Segurança, nos termos do capítulo VII da Carta.

Portanto, sob a perspectiva estritamente positivista, o Direito Internacional Convencional não prevê a hipótese do "direito de intervenção humanitária", por mais nobre que seja o propósito declarado por qualquer membro da comunidade internacional. De igual modo, não encontra aval no Direito Consuetudinário, vez que não se observa prática estatal reiterada nem o entendimento de que ela estaria em consonância com o direito (opinio jurissivenecessitatis).

Apesar da proibição supracitada, em face dos entraves operacionais do Conselho de Segurança da ONU, até a década de 1980, alguns Estados interviram, individualmente, em outros, justificando o uso da força para proteção de direitos humanos. Na década de 1990, coalizões informais de Estados ou sob o controle de organizações regionais incrementaram as intervenções supostamente para combater violações massivas de direitos humanos.

O instituto da "intervenção humanitária" levanta questões de altíssima indagação jurídica e moral. Pode uma conduta que emprega o uso da força armada e participa de uma situação de guerra ser considerada uma ação humanitária? A intervenção armada é intrinsecamente uma violação 
dos direitos humanos? É legítima e justificável, no âmbito das relações internacionais, a ação bélica para proteger os direitos humanos? Será possível converter o uso da força em elemento de proteção e garantia dos direitos humanos sem se transmutar em uma genuína guerra? Há interesse da comunidade internacional em agir em Estados falidos, destituídos de recursos naturais valiosos ou que não estejam situados em regiões estratégicas? Poderá a comunidade internacional agir quando ferir interesses de grandes potências?

O instituto da "responsabilidade de proteger" foi criado pela Comissão Internacional sobre Intervenção e Soberania Estatal (ICISS), em 2001. A Comissão foi instituída para estudar a possibilidade de a comunidade internacional intervir para fins humanitários. Seu relatório, denominado "A responsabilidade de proteger", concluiu que a soberania dava ao Estado o direito de gerir seus assuntos e lhe conferia o dever primordial de proteger a população dentro de suas fronteiras. Entretanto, o documento propôs que, quando um Estado não protegesse sua população, por falta de capacidade ou de vontade, a comunidade internacional deveria intervir.

O princípio da responsabilidade de proteger foi referendado em outros documentos das Nações Unidas, inclusive pela Resolução 1/60 da Assembleia Geral, documento final da reunião de cúpula de chefes de Estados e governos de setembro de 2005 , por ocasião do $60^{\circ}$ aniversário da ONU. Os Estados participantes da Cúpula Mundial de 2005 acordaram que a responsabilidade de proteger aplica-se somente aos crimes internacionais mais graves, quais sejam, genocídio, limpeza étnica e crimes de guerra e de lesa-humanidade. Os pressupostos da responsabilidade de proteger foram assentados em, 2009, no relatório denominado "Implementando a Responsabilidade de Proteger", da Secretaria Geral da ONU.

O primeiro pressuposto do princípio supracitado versa sobre a responsabilidade básica que incumbe o Estado de proteger sua população dos quatro crimes mencionados e de sua incitação. O segundo consiste no compromisso da comunidade internacional de auxiliar os Estados a cumprirem as obrigações relacionadas com a responsabilidade de proteger, por meio de cooperação internacional destinada a reforçar a capacidade de proteger sua própria população e a prestar assistência. O terceiro consiste na responsabilidade da comunidade internacional de atuar coletivamente, quando se torna evidente que o Estado não protege sua população frente aos quatro crimes mencionados.

Segundo esse conceito, os Estados têm a responsabilidade de proteger suas populações contra crimes de guerra, crimes contra a humanidade, 
genocídio e limpeza étnica. A comunidade internacional tem o dever de auxiliar os Estados a cumprirem essa obrigação. Caso o Estado não esteja em condições ou disposto a proteger suas populações, a comunidade internacional deve agir em conformidade com os termos da Carta das Nações Unidas, inclusive por intermédio do Conselho de Segurança. Essa responsabilidade assegura, assim, a obrigação de todos os Estados de protegerem suas populações e se orienta pelo direito internacional.

A comunidade internacional pode responder às crises humanitárias de diversas formas, por meios diplomáticos, humanitários e alternativas pacíficas, previstas na Carta das Nações Unidas, nos capítulos VI e VIII. Por último, pode-se recorrer às medidas coercitivas, previstas no capítulo VII da Carta da ONU, as quais envolvem sanções econômicas, políticodiplomáticas, jurídicas e, em casos extremos e excepcionais, uso de intervenção armada.

A obra em resenha é fruto de minuciosa pesquisa. Aborda principalmente a vertente militar da responsabilidade de proteger, sem esquecer as questões históricas e correlatas. A autora destaca que a intervenção militar, tradicionalmente denominada intervenção humanitária, não é o único instrumento da responsabilidade de proteger, nem o mais importante. A atuação preventiva sempre é o melhor remédio para evitar conflitos e solucionar crises que levam a graves e massivas violações de direitos humanos. Sob essa ótica, os pressupostos primeiro e segundo e o primeiro mecanismo do terceiro pressuposto (meios pacíficos, diplomáticos, humanitários) do princípio da responsabilidade de proteger são os instrumentos que mais se harmonizam com o objetivo de resguardar as populações de violência massiva.

O uso da força armada deve ser o último recurso, entretanto, essa é a questão mais espinhosa e controvertida, por isso vem despertando interesse e provocando acirrados debates doutrinários. Conforme afirma a autora, a tarefa da Filosofia é formular interrogantes mais que as resolver, dar conta das inquietudes humanas mais que dar respostas prontas e acabadas. Nessa perspectiva, a responsabilidade de proteger constitui tema excepcional para a reflexão da Filosofia ética, política e jurídica.

Há que se destacar que a intervenção humanitária não é questão de agora. Tem longa tradição doutrinária, remontando, pelo menos a Francisco de Vitoria, ou, segundo alguns, a Santo Agostinho. Como se nota, o objeto do livro é tema clássico não só do Direito Internacional, mas também da Filosofia do Direito, ao passo que constitui problema da máxima relevância contemporânea. 
Nos últimos anos, as crises humanitárias multiplicaram-se em diversas regiões do mundo, em consequência de sangrentos conflitos armados. Tal conjuntura destaca o debate sobre a existência ou não do dever moral e/ou do direito a intervir. A questão torna-se candente nos dias atuais, em face da intervenção na Líbia em 2011 e da crise síria iniciada na primavera do mesmo ano, que continua a se agravar desde então. A ONU prevê que cerca de 4,25 milhões de sírios se tornarão refugiados em 2014 dentro ou fora do país. Fato que levanta sérias dificuldades para abrigar, alimentar e fornecer água e saneamento básico para campos de refugiados, escolas para crianças e cuidados com idosos, feridos e enfermos. Estima-se que pelo menos 115.206 pessoas morreram no conflito sírio, entre combatentes e civis, número que aumenta a cada dia. $\mathrm{O}$ uso de armas químicas causou cerca de 1.440 mortos, incluindo centenas de crianças.

No campo do estudo da intervenção humanitária, a questão que mais interessa, sob a ótica da Filosofia do Direito, é a de sua justificação. A indagação nuclear a ser desvendada é saber em que medida pode-se considerar justificado (ou não) o recurso à força armada para proteger populações sujeitas a ameaças de violações de direitos humanos graves e massivas, ou seja, saber com base em quais critérios pode-se tomar tal decisão. A autora do livro vai ao âmago da questão controversa, ao perscrutar os fundamentos que podem legitimar a intervenção humanitária.

A obra expõe a contradição de se pôr em marcha uma guerra em defesa dos direitos humanos. Seria aceitável tal guerra? Segundo a autora, a intervenção humanitária dificilmente seria justificável mediante promoção de uma guerra, nos moldes tradicionais, em nome da defesa dos direitos humanos. Ao contrário, só seria admissível na medida em que se promova modalidade de ação militar distinta da guerra. Entretanto, reconhece a autora que a experiência das pretendidas intervenções humanitárias acabou por se converter em guerras. A intervenção na Líbia representa o exemplo mais eloquente de desvio de finalidade do princípio da intervenção humanitária. A experiência constitui o laboratório para reflexão jusfilosófica sobre a necessidade de articular o uso lícito da força no âmbito internacional de modo a não originar uma guerra.

A autora deixa claro que a intervenção humanitária não deve ser justificada como instrumento de justiça retributiva, ou seja, como castigo ou sanção por violações de direitos humanos. $\mathrm{O}$ instituto orienta-se por critérios de justiça restaurativa e reparadora, destinado, em curto prazo, a proteger as vítimas e, a médio e longo prazo, a assentar as bases para a estabilidade política, a reconciliação e a paz duradoura. Esses objetivos 
só podem ser alcançados se o uso da força revestir-se de características muito distintas e, inclusive opostas, às da guerra propriamente dita.

O livro estrutura-se em dois capítulos e considerações finais. À primeira vista, pode-se ter a impressão de que o número de capítulos reflita abordagem resumida. Ledo engano. Além de seu aspecto didático, a obra caracteriza-se por uma abordagem completa e profunda dos diversos elementos envolvidos na análise da questão.

O primeiro capítulo divide-se em nove tópicos, nos quais são delineados os fundamentos e os contornos evolutivos da responsabilidade de proteger. O primeiro tópico aborda as novas guerras e a euforia humanitária dos anos 1990. O segundo, o conceito de intervenção humanitária. O terceiro, a interseção do instituto entre a guerra justa e a defesa dos direitos humanos, no qual revisita os ensinamentos de Santo Agostinho, a defesa do inocente, de Tomás de Aquino, e a reparação das injustiças, de Francisco de Vitoria, e seu enfoque baseado na universalidade dos direitos, sem esquecer de Grócio. O quarto revisita o Direito internacional clássico e o princípio da não intervenção. $\mathrm{O}$ quinto estuda a intervenção humanitária no sistema consagrado pela Carta das Nações Unidas. O sexto analisa a influência da Guerra Fria e o paradigma legalista estrito sobre a responsabilidade de proteger. O sétimo capítulo versa sobre a evolução do instituto na década de 1990 e os precedentes da responsabilidade de proteger. O oitavo aborda a guerra de Kosovo e a ruptura do consenso construído a duras penas até então. $\mathrm{O}$ nono trata do debate atual sobre intervenção humanitária, enfrentando as diversas correntes teóricas, como o realismo estratégico, o soberanismo pluralista, o liberalismo intervencionista e a tradição da guerra justa. Este último tópico consiste numa exposição sintética, sistemática e crítica das distintas posições políticas e doutrinárias que perpassam o debate atual sobre a intervenção humanitária e também sobre a responsabilidade de proteger.

Em breve síntese, o capítulo primeiro analisa criticamente a evolução da responsabilidade de proteger, com especial ênfase na década de 1990, durante a qual problemas humanitários resultantes de conflitos étnicos causaram enorme preocupação à comunidade internacional. Deslocamentos de populações, o retorno de campos de concentração, fome, mortes e violências massivas e graves de direitos humanos causados por conflitos armados internos trouxeram à memória lembranças dos momentos mais trágicos já vividos pela humanidade e alertaram a comunidade internacional sobre os perigos da inércia e a necessidade de ação internacional concertada para fazer frente às crises humanitárias. 
A autora analisa criticamente o conceito e a legitimidade moral, política e jurídica da intervenção humanitária, bem como sua trajetória doutrinária na interseção entre a teoria da guerra justa e a teoria dos direitos humanos. Trata da posição jurídica positiva do instituto no sistema da Carta das Nações Unidas, com especial ênfase na evolução da interpretação do capítulo VII da Carta na década de noventa, período no qual são encontrados os precedentes do principio da responsabilidade de proteger.

O segundo capítulo aborda a evolução da responsabilidade de proteger, analisando desde o Relatório da Comissão Internacional a respeito da Intervenção e Soberania Estatal da ONU sobre responsabilidade de proteger até a intervenção na Líbia. O capítulo é composto de cinco tópicos. O primeiro versa sobre o mencionado relatório, envolvendo a análise do instituto da soberania como responsabilidade, a segurança humana e o princípio emergente da responsabilidade de proteger. Trata das dimensões da responsabilidade de proteger, com especial ênfase à prevenção, da intervenção militar e suas premissas: causa justa, intenção correta, esgotamento de todos os recursos, meios proporcionais e possibilidades razoáveis de êxito e a complexa questão da autoridade competente. $\mathrm{O}$ primeiro tópico é encerrado com a análise valorativa e interpretativa do Relatório da ICISS. O segundo tópico enfatiza a importância de se diferenciar o instituto da responsabilidade de proteger com relação à guerra contra o terrorismo. O terceiro aborda a evolução do instituto desde o relatório da ICISS até o Documento Final da Cúpula da ONU de 2005. O quarto tópico trata da consolidação da responsabilidade de proteger e o quinto, da Resolução 1973 do Conselho de Segurança da ONU e da intervenção militar na Líbia, discutindo-se a legalidade e a legitimidade dessa ingerência.

No segundo capítulo, a autora analisa, cronologicamente, a doutrina da responsabilidade de proteger e sua evolução no âmbito internacional. Examina a sequência de iniciativas e documentos internacionais, por meio dos quais foi perfilando-se e consolidando-se paulatinamente. Começa com o Relatório de dezembro de 2001 da ICISS até sua aplicação na intervenção na Líbia, em março de 2011.

No que tange à intervenção militar com fins de proteção humana, a autora examina detalhadamente os requisitos de sua admissibilidade, contidos no Relatório sobre Responsabilidade de Proteger, o qual se apoia em boa medida na doutrina e na terminologia embutida na tradição da guerra justa (causa justa, intenção correta, último recurso, meios proporcionais, possibilidades razoáveis de êxito e autoridade legítima). 
O requisito de autoridade legítima para decidir intervir ou não por motivo de humanidade reveste-se de especial complexidade e dificuldade em virtude da polêmica sobre a admissibilidade ou não de intervenção humanitária unilateral por parte de um Estado e do caráter de órgão eminentemente político do Conselho de Segurança da ONU e o risco de paralisação deste por exercício ou ameaça de exercício do direito de veto.

É interessante observar que a publicação do Relatório sobre Responsabilidade de Proteger coincidiu com a adoção da denominada "guerra contra o terrorismo", contexto no qual se produziram intervenções unilaterais lideradas pelos Estados Unidos. Como a invasão do Afeganistão e a guerra do Iraque foram completamente alheias a propósitos humanitários, faz-se necessário esforço de clarificação destinado a pôr manifesto às evidentes diferenças entre tais ações e uma hipotética intervenção com fins de proteção humana, em circunstâncias extremas e com autorização do Conselho de Segurança da ONU.

O capítulo segundo encerra-se com detalhada análise da intervenção na Líbia em 2011. Tomado como caso paradigma, a autora destaca as dificuldades de se colocar em prática a doutrina da responsabilidade de proteger na vertente de uso da força. No momento de autorizar essa intervenção, foram feitos evidentes esforços para cumprir com as exigências da doutrina da responsabilidade de proteger. Não obstante, sua legitimidade foi questionável e desde o início a intervenção degenerou em autêntica guerra, destinada a apoiar os rebeldes e a mudar o regime, derrubando o Coronel Kadafi.

Nas considerações finais, além de recapitular e sistematizar as questões basilares da responsabilidade de proteger, a autora focaliza dois aspectos que lhe pareceram particularmente complexos e controvertidos. O significado jurídico da responsabilidade de proteger e como evitar que esse tipo de intervenção, que tem ou deve ter objetivos diferentes aos da guerra, acabe se convertendo em autênticas guerras.

Frente ao debate acerca da natureza jurídica ou política da responsabilidade de proteger, a autora se inclina pela primeira posição. Em sua ótica, a opinião coletiva dos Estados, manifestada no Documento Final da Cúpula Mundial de 2005, que tinha como objetivo promover reforma abrangente da Organização das Nações Unidas, teria valor de opinio iuris.

No que diz respeito à intervenção militar, a responsabilidade de proteger teria alcance de norma meramente autorizativa, correspondendo ao Conselho de Segurança a competência não só prioritária, mas exclusiva para autorizá-la, ainda assim, respeitando-se os limites instituídos 
pelo Documento Final da Cúpula de 2005. Logo, a intervenção militar estaria condicionada ao alcance do umbral da justa causa, que vincula a responsabilidade de proteger aos crimes internacionais mais graves (genocídio, crimes de guerra, limpeza étnica e crimes de lesa-humanidade) e ao esgotamento dos meios pacíficos ou que estes resultem inadequados.

Com relação à admissibilidade da intervenção humanitária unilateral, a autora entende que a intervenção não autorizada não só é ilegal (de lege data), mas também de lege ferenda. Ressalta que, na esfera regulada pelo Direito Internacional, não se deve permitir que atores individuais atuem em suas relações recíprocas de acordo com seus próprios critérios acerca do que é justo ou injusto, ou certo ou errado. Com maior razão ainda em matéria de tamanha transcendência, como é o uso da força. No caso das organizações regionais que atuam fora de seu âmbito de jurisdição, a inadequação da intervenção unilateral torna-se ainda mais evidente.

Portanto, qualquer intervenção humanitária, mediante uso de força, deve ser submetida à autoridade competente. Apesar dos obstáculos que o funcionamento do Conselho de Segurança comporta e do questionamento de sua autoridade, em razão de sua composição e de seu déficit democrático, ele é a única autoridade competente para autorizar uma intervenção militar em conformidade com o Direito Internacional vigente. Enquanto vigorar esse sistema, a decisão do Conselho de Segurança é insubstituível por qualquer outra organização ou Estado.

Nesse contexto, como ficariam os casos-limites nos quais o Conselho de Segurança encontre-se bloqueado por contingências políticas e os pressupostos para se intervir configurem uma obrigação moral? $\mathrm{Na}$ hipótese, segundo a autora, a intervenção unilateral pode se justificar, juridicamente, como estado de necessidade, o qual configura exceção à regra no caso concreto, porém sem suprimi-la como tal, salvaguardando sua validez com caráter geral.

Ao longo do trabalho, a autora enfatiza as dificuldades que levanta, desde suas origens, em Francisco de Vitoria, a ideia e, sobretudo, a colocação em prática da intervenção bélica em defesa dos direitos humanos. Tais dificuldades afetam tanto a tradicional intervenção humanitária, como a atual responsabilidade de proteger em sua vertente de intervenção armada.

Essas dificuldades são de três ordens. A primeira reside na ambígua configuração a meio caminho entre o dever moral e o direito de intervir, que atualmente se reflete no caráter meramente permissivo da norma que autoriza o Conselho de Segurança a intervir para impedir ou deter 
atrocidades massivas. A segunda trata do risco de sua instrumentalização a serviço do imperialismo ou, de modo mais geral, a serviço dos interesses dos poderosos. Já a terceira ordem aborda a contradição não só lógica, mas também, sobretudo, existencial que supõe a ideia de empreender uma guerra em defesa dos direitos humanos.

De acordo com Fernández, nenhuma dessas dificuldades admite resposta unívoca. Entretanto, a impossibilidade de alcançar respostas incontestáveis não deve ser considerada deficiência, mas, sim, o melhor antídoto contra o dogmatismo. Certo é que, ante o dilema de intervir militarmente por causas humanitárias ou não fazer nada, nunca se pode ter a certeza de estar fazendo o correto.

Para a autora, qualquer decisão que se adote em situação de grave e massiva violação de direitos humanos será sempre trágica. Tal afirmação contrasta com a atitude de triunfalismo moral, com a certeza acerca do caráter moralmente justificado de sua ação de que em certas ocasiões vangloriaram os promotores desse tipo de intervenções. Os casos de Kosovo e Líbia são os exemplos mais ilustrativos nesse sentido.

O problema que perpassa toda a obra resenhada desagua na seguinte questão: como superar os obstáculos acima citados para evitar que a intervenção humanitária converta-se em autêntica guerra sem excluir por completo o uso da força em casos extremos? A autora discorre de forma elegante, competente e profunda, tanto do ponto de vista teórico quanto prático, sobre a saída desse verdadeiro quebra-cabeça.

Por fim, vale recordar que a autora, desde o início, alerta que a discussão sobre intervir com meios de morte para salvar vidas leva à reflexão sobre a necessidade de se articular políticas que estabeleçam condições de paz, desenvolvimento e vida digna para todos os seres humanos. Nesse sentido, a melhor forma para evitar o uso da força bélica é articular, seriamente, ações preventivas que evitem o surgimento de situações desencadeadoras de violações massivas e graves de direitos humanos. A comunidade internacional fará melhor se adotar conduta proativa, no sentido de promover a paz e investir na desmontagem das estruturas injustas que potencializam os conflitos em diversos rincões da Terra.

Recebida: outubro/2013. 